\title{
Developmental and Genetic Components Explain Enhanced Pulmonary Volumes of Female Peruvian Quechua
}

\author{
Melisa Kiyamu, ${ }^{1 \star}$ Abigail Bigham, ${ }^{2}$ Esteban Parra, ${ }^{3}$ Fabiola León-Velarde, ${ }^{4}$ María Rivera-Chira, ${ }^{4}$ \\ and Tom D. Brutsaert ${ }^{5}$ \\ ${ }^{1}$ Department of Anthropology, University at Albany, SUNY, Albany, NY 12222 \\ ${ }^{2}$ Department of Anthropology, University of Michigan, Ann Arbor, MI 48109 \\ ${ }^{3}$ Department of Anthropology, University of Toronto at Mississauga, Toronto, Canada L5L 1 C6 \\ ${ }^{4}$ Departamento de Ciencias Biológicas y Fisiológicas, Universidad Peruana Cayetano Heredia, Lima, Peru \\ ${ }^{5}$ Department of Exercise Science, Syracuse University, Syracuse, NY 13210
}

KEY WORDS hypoxia; adaptation; development; genetics

\begin{abstract}
High altitude natives have enlarged vital capacities and residual volumes (RV). Because pulmonary volumes are an indication of functionally relevant traits, such as diffusion capacity, the understanding of the factors (genetic/developmental) that influence lung volumes provides insight into the adaptive responses of highlanders. In order to test for the effect of growth and development at high altitude on lung volumes, we obtained forced vital capacities (FVC), RV, and total lung capacities (TLC) for a sample of 65 Peruvian females of mostly Quechua origins (18-34 years) who were sub-divided into two well-matched groups: 1) sea-level born and raised females (BSL, $n=34$ ) from Lima, Peru (150 m), and 2) high-altitude born and raised females (BHA, $n=31$ ) from Cerro de Pasco, Peru (4,338 m). To determine Quechua origins, Native American ancestry proportion (NAAP) for each
\end{abstract}

Early studies in the Andes suggested that native highlanders had a set of particular traits related to life at high altitude, including certain cardiorespiratory features and a high exercise capacity (Monge, 1948). Among these traits, pulmonary volumes were one of the best documented, and there is no doubt that high altitude natives have enhanced lung volumes relative to lowlanders (Harrison et al., 1969; Frisancho et al., 1973; Boyce et al., 1974; Droma et al., 1991; Greksa et al., 1987, 1994; Greksa, 1996). Enlarged pulmonary volumes could be associated with higher diffusion capacities by increasing the total surface area of the alveoli, implying genetic adaptation to hypoxia. Indeed, some studies have suggested an important role of genetics in determining lung volumes in Andeans (Greksa, 1996; Frisancho et al., 1997). More recently, genome-wide studies of both Tibetans and Andeans have refocused interest on the genetic possibility by revealing strong signals of natural selection in several genes (Beall et al., 2010; Bigham et al., 2010; Simonson et al., 2010; Yi et al., 2010). In Himalayans, three of these genes were shown to be associated with low hemoglobin which is one of the characteristics of Tibetan populations (Beall et al., 2010; Simonson et al., 2010). While these studies did not examine lung volumes, they do offer the first direct support for the hypothesis that both Andeans and Tibetans are genetically adapted to high altitude. individual was assessed using a panel of 70 ancestry informative markers. NAAP was similar between groups $(\mathrm{BSL}=91.71 \% ; \mathrm{BHA}=89.93 \% ; P=0.240)$, and the analysis confirmed predominantly Quechua origins. After adjusting for body size and NAAP, BHA females had significantly higher FVC $(3.79 \pm 0.06 \mathrm{l} ; P<0.001)$, RV $(0.98$ $\pm 0.03 \mathrm{l} ; P<0.001)$ and TLC $(4.80 \pm 0.07 \mathrm{l} ; P<0.001)$ compared to BSL females $(\mathrm{FVC}=3.33 \pm 0.05 \mathrm{l}$; $\mathrm{RV}=$ $0.69 \pm 0.03 \mathrm{l}$; TLC $=4.02 \pm 0.06 \mathrm{l})$. NAAP was not associated with FVC $(P=0.352)$ or TLC $(P=0.506)$. However, NAAP was positively associated with $\operatorname{RV}(P=0.004)$. In summary, results indicate that developmental exposure to high altitude in females constitutes an important factor for all lung volumes, whereas both genetic and developmental factors seem to be important for RV. Am J Phys Anthropol 148:534-542, 2012. @2012 Wiley Periodicals, Inc.
An alternate explanation is that Peruvian Quechua are developmentally adapted to hypoxia (Frisancho, 2009). Indeed, there is overwhelming evidence for the developmental contribution to the enlargement of human lungs, both in altitude natives and lowlanders born and raised at high altitude (Frisancho et al., 1973; Greksa, 1990). Experimental animal studies, in a number of different species, have also shown a strong effect of hypoxia on lung growth and development (Bartlett and Remmers, 1971; Burri and Weibel, 1971; Cunningham

\footnotetext{
This article was published online on 3 May 2012. An error was subsequently identified. This notice is included in the online and print versions to indicate that both have been corrected on 14 June 2012 .

Grant sponsor: NSF; Grant number: BCS-0129377.

*Correspondence to: Melisa Kiyamu, Department of Anthropology, 1400 Washington Ave, The University at Albany, SUNY, Albany, New York 12222, USA. E-mail: mkiyamut@syr.edu
}

Received 12 August 2011; accepted 6 March 2012

DOI 10.1002/ajpa.22069

Published online 3 May 2012 in Wiley Online Library (wileyonlinelibrary.com). 
et al., 1974; Lechner and Banchero, 1980; Johnson et al., 1985; Faridy et al., 1988).

The factors that regulate the enlarged pulmonary volumes of highlanders are complex. However, the examination of developmental and/or genetic roles on this enhancement is useful to address the broader question of evolutionary adaptation to high altitude, which is one of the central research questions in comparative high altitude studies (Hochachka et al., 1999; Beall, 2000; Moore, 2001; Rupert and Hochachka, 2001). A proper partition of developmental and genetic factors is a challenging task, given the interaction of both factors to determine complex physiological phenotypes. The common approach to partition these factors has been the migrant study design (Harrison, 1966). However, migration studies depend on the comparison of distinct groups based on the assumption that group differences are not confounded by genetic, socioeconomic, and/or lifestyle factors. This is often not the case. In previous studies including European and Andean subjects, European participants tend to be taller, heavier, less physically active, and of higher socioeconomic status than Quechua participants (Greksa, 1986; Frisancho et al., 1997; Brutsaert et al., 1999). A better approach is to use study groups that were matched on body size, considering the importance of (especially) height in explaining the lung size variation. For developmental effects, in particular, the ideal study would also match on some measure of ancestry. The need for ancestry analysis in this region is based on the history of population contact between Europeans, Quechua natives and to a lesser degree, West African populations. Surname analysis and skin reflectance have both been used to assess ancestry (Chakraborty, 1989; Greksa, 1996), but the validity of skin reflectance in Andean studies has been questioned (Brutsaert et al., 2004). Fortunately, a new molecular approach is available to measure the ancestry proportion of individuals using a panel of ancestry-informative markers (AIMs). This approach has been used successfully to infer the underlying genetic basis for several phenotypic traits, including skin pigmentation (Parra et al., 2004), oxygen saturation (Bigham et al., 2010), pulmonary volumes and exercise phenotypes (Brutsaert et al., 2004), as well as uterine artery blood flow (Wilson et al., 2007) and birth weight (Julian et al., 2009). The general approach has been described in detail elsewhere (Shriver et al., 2003).

In this study, we aimed to test the developmental hypothesis on pulmonary volumes, using a version of the migrant approach, and the use of ancestry informative markers (AIMS), based on the comparison of two groups of wellmatched females, who differed in their exposure to hypoxia during the period of growth and development (i.e. Peruvian Quechua females born and raised at high altitude $(4,338 \mathrm{~m})$ and at sea-level $(150 \mathrm{~m})$ ). We used a panel of 70 AIMS in order to both control for and evaluate the effect of genetics on pulmonary volumes. This study is novel in that: 1) residual volumes and total lung capacities (TLC) are reported, values which only a few studies have reported in the previous literature for adult Quechua women; 2) the study groups are well-matched, with similar Native American Ancestry Proportion (NAAP) and height; and 3) ancestry was assessed in both groups, using a valid molecular approach.

\section{MATERIALS AND METHODS Subjects}

Sixty-five female subjects, aged 18-34, were recruited and tested in Lima, Peru $(150 \mathrm{~m})$ and Cerro de Pasco, Peru $(4,338 \mathrm{~m})$. a. Thirty-four female subjects were recruited in Lima, Peru (altitude $150 \mathrm{~m}$ ), in the district of Barrios Altos, San Juan de Lurigancho, where there is a high percentage of recent migrants from high altitude. The criteria of inclusion for this group included being born and raised in Lima or near sea level $(<150 \mathrm{~m})$, and having both sets of their parents and grandparents born at high altitude $(>3,000 \mathrm{~m})$. Also, none of them had any exposure to hypoxia during growth (i.e., none of the females in this group had traveled to any high altitude place). This group will be referred as BSL (born at sea level).

b. At high altitude, 31 subjects were recruited from the locality of Cerro de Pasco, Peru (altitude 4,338 m). The criteria of inclusion for this group included being born and raised at high altitude $(>3,000 \mathrm{~m})$ and having both sets of their parents and grandparents born either at Cerro de Pasco or at an altitude higher than $3,000 \mathrm{~m}$. Also, none of these subjects had any exposure to normoxia during growth, ensuring a full-developmental exposure to hypoxia (i.e., none of the females in this group had traveled to any low altitude location, $<3,000 \mathrm{~m}$ ). This group will be referred as BHA (born at high altitude).

Before being accepted into the study, all female subjects were screened by a physician and interviewed to assess their eligibility. For logistical reasons, the study did not allow for Quechua ancestry screening via molecular methods a priori, so interviews were conducted to document surnames (from the paternal and maternal lineages). Quechua ancestry was determined by 1) the presence of Quechua surnames from both parental lineages (parents and grandparents). In Peru, the official names include retention of both maternal and paternal surnames, so we registered the surnames up to two generations (grandparents), for a total of eight surnames. Quechua ancestry was based on the presence of three or more Quechua surnames; 2) volunteers identified themselves as having ancestors from the Andes; 3) knowledge of the Quechua language by themselves and/or at least one of their parents or grandparents (given that Quechua is not taught at school and only transmitted in the family environment); 4) confirmation of having $>60 \%$ NAAP, assessed via molecular analysis using a panel of 70 AIMS.

Medical examinations were conducted by the physician to exclude individuals with the following: a) clinical history for cardiovascular, respiratory, and/or renal problem, in particular any obstructive or restrictive respiratory disease, following the medical guidelines for expected FEV1/FVC(\%), forced vital capacities (FVC) and FEV1 in healthy individuals, b) present or past history of smoking, c) individuals who were pregnant, d) individuals taking oral contraceptives, and e) $[\mathrm{Hb}]$ lower than $11 \mathrm{~g} / \mathrm{dl}$ for the BSL group and lower than $13 \mathrm{~g} / \mathrm{dl}$ for the BHA group. Polycythemic individuals at altitude were also excluded from the study ([Hb] higher than 19 $\mathrm{g} / \mathrm{dl})$. Hemoglobin concentration was measured using a Hemocue analyzer (Hemocue, Angelholm, Sweden) from blood samples obtained by finger-stick.

All individuals were recruited with the help of local liaisons in each location; and they came from similar socioeconomic backgrounds, as inferred from their level of education and current profession. The female volunteers constitute a sub-group of a larger study that tested the association of the angiotensin-converting enzyme (ACE) genotype and oxygen saturation $\left(\mathrm{SaO}_{2}\right)$, as well as 
the hypoxic ventilator response (HVR); therefore, the criteria for inclusion and exclusion also met the requirements for a different study conducted by our research team (Bigham et al., 2008). Lung volumes (FVC) for the male counterparts of the study were reported elsewhere (Brutsaert et al., 2004).

All subjects received an oral explanation of the measurements to be made and questions from the potential participants were addressed by the investigators. All subjects gave their written informed consent to participate in the study. This research project was approved by the Institutional Review Board of the University at Albany, State University of New York and Universidad Peruana Cayetano Heredia.

\section{Anthropometry}

Standard anthropometry was performed on each subject by the same investigator. Measurements included height, weight, and skinfolds at subscapular, suprailiac, biceps, and triceps sites. Body density was calculated according to age and sex specific equations given by Durnin and Womersley (1974). Percent body fat was calculated from the Siri equation (Siri, 1956).

\section{Pulmonary volumes}

Pulmonary function was assessed in Lima (altitude $150 \mathrm{~m}$ ) for BSL and at Cerro de Pasco (altitude 4,338 m) for BHA. Most of the Lima subjects also had their pulmonary function assessed in Cerro de Pasco after traveling to this high-altitude town for a different set of measurements as described in a previous paper published by the same research group (Bigham et al., 2008). The testretest (i.e., high altitude versus sea-level) average values for all static pulmonary volumes were identical, as is expected for these measures, supporting the validity of direct comparison between our two research samples. In both settings, we used a VS400 volumetric spirometer (Puritan-Bennett, Mallinckrodt, Hazelwood, MO), calibrated daily with a 3-1 liter calibration syringe. For assessing pulmonary function, each subject performed a maximal inspiration, followed immediately by a forced maximal expiration while in a seated position. From this procedure, the FVC, defined as the maximum volume of air expired after a maximal inspiration, and forced expiratory volume made in $1 \mathrm{~s}$ (FEV1) were determined based on the best of at least two efforts. FVC and FEV1 measures were corrected for BTPS (body temperature, pressure saturated).

Residual volume (RV) was obtained using the closedcircuit oxygen dilution method as developed by Wilmore et al. (1980). The FEV1/FVC ratio was used to evaluate the pulmonary function of each individual to exclude volunteers whose measurements suggested any obstructive respiratory disease. TLC was obtained by adding FVC and RV for each volunteer.

\section{Genotyping}

Genetic markers. NAAP was estimated using 70 single nucleotide polymorphisms (SNP) AIMS (rs140864, rs2065160, rs17203, rs2213602, rs3309, rs3340, rs2763, rs2161, rs2695, rs594689, rs1042602, rs1800498, rs1079598, rs2862, rs4646, PV92, rs2816, rs4884, MID161, rs16383, rs2814778, rs6003rs285, rs1800404, rs1987956, rs1415878, rs1435090, rs768324, rs1980888, rs983271, rs878825, rs386569, rs1373302, rs1891760, rs963170, rs718092, rs1808089, rs1320892, rs723822, rs1881826, rs2207782, rs1112828, rs2064722, rs2351254, rs1316579, rs1935946, rs1506069, rs719776, rs1369290, rs1465648, rs2077681, rs725416, rs1594335, rs2188457, rs1861498, rs2341823, rs1327805, rs2396676, rs1461227, rs1403454, rs717962, rs1074075, rs764679, rs724729, rs717091, rs726391, rs1487214, rs725667, rs2225251, rs951784), as previously described (Shriver et al., 2003; Bonilla et al., 2004; Brutsaert et al., 2005). The AIMs were selected based on their high frequency differences between West African, Native American, and European populations, as follows: 1) 18 markers showed high frequency differences between West African populations compared to Native American and European populations, 2) 13 markers showed high frequency differences between European compared to West African and Native American populations, 3) 31 markers showed high frequency differences between Native American compared to European and West African populations, and 4) eight of the markers showed intermediate frequency differences among all three parental populations.

\section{Ancestry estimation}

Based on each individual's genotypes at all 70 loci, NAAP was calculated using a maximum likelihood method (Hanis et al., 1986). Only a few individuals showed evidence of West African ancestry, but the inclusion or exclusion of these individuals did not affect the overall results presented in this paper.

\section{Statistical analysis}

The statistical package PAWS Statistics software (Version 18, SPSS) was used to conduct all the analysis. Variables were first tested for normality using the Kolmogorov-Smirnov test. NAAP was used both as a covariate, in analyses testing for developmental effects, and also as a primary independent variable in the analysis testing for the association of ancestry with pulmonary volumes. NAAP was right skewed and was normalized using a common logarithmic transformation. All statistical analyses were performed using the normalized variable.

An independent t-test was used to test for anthropometric differences between the highland-born and the lowland-born females. Values are shown as mean values \pm SE. ANCOVA was used to test the differences for FVC, FEV, RV, and TLC in the high altitude group and the sea-level group, while controlling for height and/or NAAP. For ANCOVA analysis, values are shown as adjusted mean values \pm SE. Finally, we used a general linear model to test for association of NAAP with components of pulmonary volumes. Statistical significance was considered at a $P$-value of less than 0.05 for all tests.

\section{RESULTS Subject characteristics}

BSL and BHA were well-matched in terms of age, height, and NAAP: none of these characteristics were significantly different in the two samples (Table 1). Weight and percentage of body fat were found to be significantly higher in BSL compared to BHA $(P=0.002$; $P<0.001$, respectively). The sum of skinfolds (biceps, triceps, subscapular, and suprailiac) were significantly higher in the BSL group compared to the BHA group $(P<0.001)$. BMI was also higher in the BSL group compared to $\mathrm{BHA}(P=0.006)$. While the latter falls under a 
TABLE 1. Anthropometric characteristics (means $\pm S E$ ) of Quechua females born and raised at high altitude (BHA), and females born and raised at sea-level (BSL)

\begin{tabular}{lrrr}
\hline & \multicolumn{1}{c}{ BSL } & \multicolumn{1}{c}{ BHA } & \\
\hline & \multicolumn{1}{c}{$(n=34)$} & \multicolumn{1}{c}{$(n=31)$} & $P$-value \\
\hline Age (years) & $24.7 \pm 0.71$ & $25.1 \pm 0.73$ & 0.679 \\
Height (m) & $1.5 \pm 0.01$ & $1.48 \pm 0.01$ & 0.273 \\
Weight (kg) & $56.4 \pm 1.05$ & $52.0 \pm 0.86$ & 0.002 \\
Body fat (\%) & $36.9 \pm 0.68$ & $32.7 \pm 0.77$ & $<0.001$ \\
Sum of skinfolds (mm) & $105.0 \pm 4.43$ & $78.5 \pm 4.24$ & $<0.001$ \\
BMI & $25.21 \pm 0.44$ & $23.61 \pm 0.34$ & 0.006 \\
Fat free mass (kg) & $35.4 \pm 0.54$ & $34.9 \pm 0.44$ & 0.756 \\
Hemoglobin (g/dl) & $13.6 \pm 0.15$ & $16.5 \pm 0.29$ & $<0.001$ \\
NAAP (\%) & $91.71 \pm 0.01$ & $89.93 \pm 0.01$ & 0.240 \\
EAP (\%) & $5.24 \pm 0.01$ & $6.71 \pm 0.01$ & 0.443 \\
AAP (\%) & $3.06 \pm 0.01$ & $3.35 \pm 0.01$ & 0.948 \\
\hline
\end{tabular}

Ancestry proportions are presented as Native American (NAAP), European (EAP), and African (AAP).

TABLE 2. Unadjusted pulmonary volumes and adjusted (means $\pm S E$ ) for height and NAAP in Quechua females born and raised at high altitude (BHA) and born and raised at sea-level (BSL) in BTPS units

\begin{tabular}{|c|c|c|c|}
\hline & BSL & BHA & $P$-value \\
\hline FVC-BTPS (1) & $3.35 \pm 0.06$ & $3.79 \pm 0.07$ & $<0.001$ \\
\hline RV-BTPS (1) & $0.71 \pm 0.03$ & $0.97 \pm 0.04$ & $<0.001$ \\
\hline FEV1-BTPS (1) & $2.81 \pm 0.07$ & $3.15 \pm 0.09$ & 0.004 \\
\hline FEV1/FVC (\%) & $83.75 \pm 0.85$ & $83.40 \pm 0.92$ & 0.886 \\
\hline TLC-BTPS (1) & $4.06 \pm 0.07$ & $4.76 \pm 0.09$ & $<0.001$ \\
\hline FVC-BTPS (1) & $3.33 \pm 0.05$ & $3.79 \pm 0.06$ & $<0.001$ \\
\hline RV-BTPS (1) ${ }^{\mathrm{a}}$ & $0.69 \pm 0.03$ & $0.98 \pm 0.03$ & $<0.001$ \\
\hline FEV1-BTPS (1) & $2.80 \pm 0.08$ & $3.16 \pm 0.08$ & 0.002 \\
\hline FEV1/FVC $(\%)^{\mathrm{a}}$ & $83.98 \pm 1.65$ & $83.16 \pm 1.73$ & 0.734 \\
\hline TLC-BTPS $(1)^{\mathrm{a}}$ & $4.02 \pm 0.06$ & $4.80 \pm 0.07$ & $<0.001$ \\
\hline
\end{tabular}

a Adjusted values for height and NAAP.

normal BMI range (23.61), the BSL group is, on average, slightly overweight (25.21). As expected, based on altitude exposure, BHA had higher levels of hemoglobin compared to the BSL group $(P<0.001)$.

\section{Pulmonary function}

Table 2 shows the pulmonary volumes for both groups, corrected for BTPS. The first part of the table contains the unadjusted means for FVC, FEV, RV, and TLC. The estimated marginal means, adjusting for height and NAAP are also presented in the second section of the table. We found that BHA had consistently larger pulmonary volumes compared to the BSL group, without adjusting for any variables. Moreover, when correcting for height and NAAP, the BHA group still had significantly higher FVC $(P<0.001)$, RV $(P<0.001)$, FEV1 $(P=0.002)$, and TLC $(P<0.001)$. As expected, the ratio FEV1/FVC was not different between groups, and it was in the range of normal values for participants without pulmonary disease, according to reference standards, that is, above $80 \%$. Figure 1a through Figure 1c show pulmonary volumes by stature. FVC by stature was higher in BHA $(3.79 \pm 0.06 \mathrm{l})$ compared to $\mathrm{BSL}(\mathrm{FVC}=$ $3.33 \pm 0.051 ; P<0.001$; Fig. 1a); RV was also higher in $\mathrm{BHA}(0.98 \pm 0.03 \mathrm{l})$ compared to $\mathrm{BSL}(0.69 \pm 0.03 \mathrm{l}, P<$
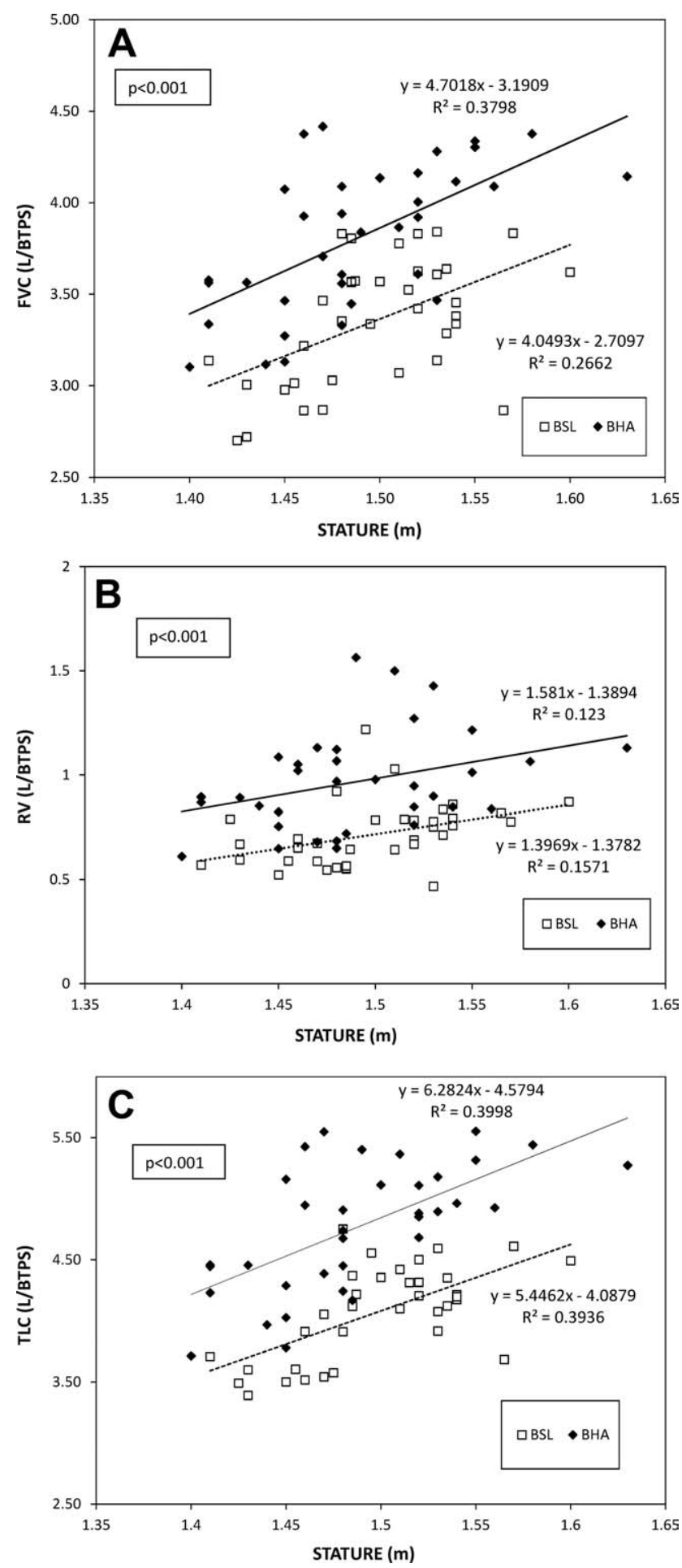

Fig. 1. a) Forced vital capacity (FVC, 1), b) Residual volume (RV,l), and c) Total lung capacity (TLC,l) plotted against stature $(\mathrm{m})$ in born at high altitude (BHA) and born at sea-level (BSL) female Quechua natives. In all cases, pulmonary volumes are corrected for BTPS. FVC, RV, and TLC are significantly larger in BHA versus BSL group $(P<0.001)$.

0.001, Fig. 1b); and BHA showed larger TLC (4.80 \pm $0.07 \mathrm{l} ; P<0.001)$ compared to BSL $(4.02 \pm 0.06 \overline{1}$, Fig. 1c). 
TABLE 3. General linear model including height, place, logNAAP, and logNAAP* place as factors to explain the variability of pulmonary volumes (FVC, RV, and TLC)

\begin{tabular}{|c|c|c|c|c|c|c|c|c|c|}
\hline & \multicolumn{3}{|c|}{ FVC } & \multicolumn{3}{|c|}{$\mathrm{RV}$} & \multicolumn{3}{|c|}{ TLC } \\
\hline & $\beta$ & $P$-value & $R^{2}$ & $\beta$ & $P$-value & $R^{2}$ & $\beta$ & $P$-value & $R^{2}$ \\
\hline Model & & & 0.513 & & & 0.428 & & & 0.623 \\
\hline Height & 5.011 & $<0.001$ & 0.335 & 1.563 & 0.004 & 0.131 & 6.574 & $<0.001$ & 0.391 \\
\hline Group $^{a}$ & -0.529 & 0.001 & 0.179 & -0.325 & $<0.001$ & 0.203 & -0.854 & $<0.001$ & 0.296 \\
\hline Log NAAP & -0.339 & 0.352 & 0.002 & 1.183 & 0.004 & 0.079 & 0.843 & 0.506 & 0.01 \\
\hline LogNAAP* group & -0.457 & 0.707 & 0.002 & -0.288 & 0.677 & 0.003 & -0.745 & 0.599 & 0.005 \\
\hline
\end{tabular}

${ }^{\text {a }}$ For group variable, the effects coding refers to being born and raised at sea-level.

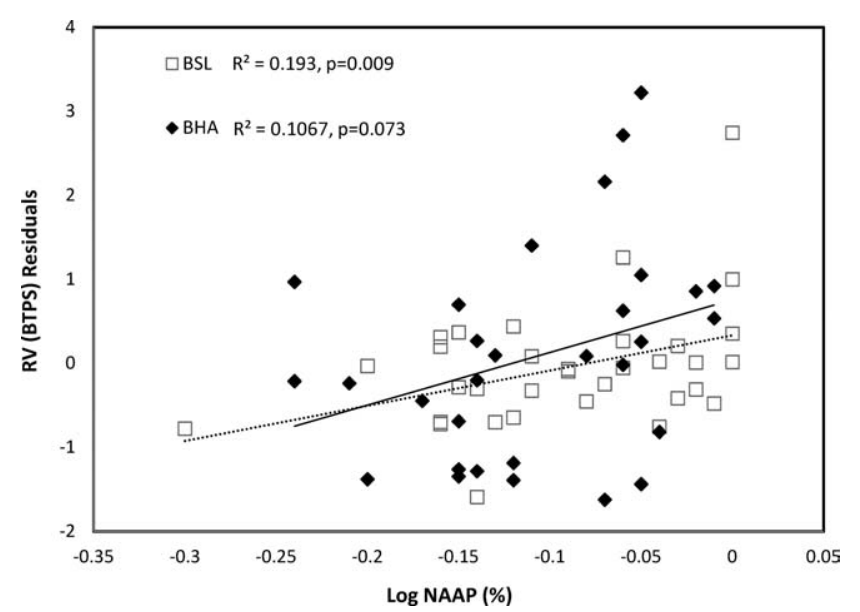

Fig. 2. RV-BPTS residuals (adjusted for height) plotted against log NAAP $(\%)$ for BHA and BSL.

\section{Pulmonary volumes and NAAP}

As previously described, the BSL and BHA groups were well-matched for NAAP (91.71 and 89.93\%, respectively, $P=0.240)$. In order to evaluate the association of NAAP and each pulmonary volume, we used a general linear model (GLM) to run covariance models, including height and group (i.e., place of birth) as main effects and LogNAAP and interaction effects (LogNAAP*group). The results are given in Table 3. As expected, height and study group were highly significant predictors of the FVC, RV and TLC in all models tested. There was no significant association between NAAP and FVC $(P=0.352)$ or NAAP and TLC $(P=0.506)$. However, there was an association between NAAP and RV $(P=0.004)$, after controlling for the effects of height and study group. No interaction effect was detected between LogNAAP and group for any of the pulmonary volumes. Figure 2 shows the standardized residuals of RV (adjusted for height) plotted against the natural log of NAAP, for each group. In the BSL group, there was a positive significant association between NAAP and RV $\left(R^{2}=0.1938, P=0.009\right)$, and the BHA group also showed a trend for a positive association between NAAP and RV $\left(R^{2}=0.1065, P=\right.$ 0.073).

\section{DISCUSSION}

The main finding of this study is that developmental exposure to hypoxia determines enlarged pulmonary volumes (FVC and TLC), whereas both developmental and genetic factors determine enlarged RV in a sample of Peruvian Quechua females. Unlike previous studies, this conclusion is based on a comparison of two very wellmatched groups, who were nearly identical for ancestry and body size. This is an important consideration as both factors are potential confounders, either putatively, as in the case of genetics, or directly, as in the case of body size. Highland-born females had 15-42\% higher FVC, TLC, FEV1, and RVs compared to sea-level born subjects. This difference might represent a physiologically significant advantage, especially for higher diffusion capacities, considering the normal range of variation $(\sim 20 \%)$ in these measures. Moreover, we also found an association between NAAP and RV, suggesting that Andean evolutionary history has also played a role in determining the large lungs and, possibly, the gas exchange characteristics of this population. Below, we consider the developmental and genetic hypotheses independently, and then consider the functional implications of large lungs in Peruvian Quechua, as well as the differential timing of exposure to hypoxia.

\section{Developmental components of pulmonary volumes}

Previous studies provide strong support that developmental exposure to hypoxia increases lung volumes, both in high altitude native populations, and non-native populations who were born and raised at altitude (Frisancho et al., 1973; Greksa, 1990; Droma et al., 1991; Greksa et al., 1994; Brutsaert et al., 1999; Weitz et al., 2002). Experimental studies in animals also support the hypothesis showing enhanced lung growth in rats, dogs, and guinea pigs (Burri and Weibel, 1971; Lechner and Banchero, 1980; Johnson et al., 1985; Sekhon and Thurlbeck, 1996a,b). Consistent with these studies, we also found a strong developmental effect on FVC, RV, and TLC. These pulmonary volumes were all significantly larger in the BHA group, after controlling for the effects of height and NAAP. Figure 3 is a summary of mean FVC values plotted against stature from previous studies, for both males and females in the Andes (Boyce et al., 1974; Mueller et al., 1978; Greksa et al., 1987, 1994; Frisancho et al., 1997; Brutsaert et al., 1999), the Himalayas (Droma et al., 1991; Weitz et al., 2002), with European populations born and raised at altitude (Frisancho et al., 1997; Brutsaert et al., 1999) and with Ethiopians (Harrison et al., 1969). Overall, in this study, BHA subjects had $\sim 11 \%$ greater FVC values than their BSL peers. These values are very similar to results in adult Andean males, reported by our study group, where FVC was $\sim 10 \%$ higher in the BHA group compared to the BSL group (Brutsaert et al., 2004). Additionally, BHA females had similar FVC values (3.79 l) to those reported in the literature for Andean women, which range from 3.045 to 


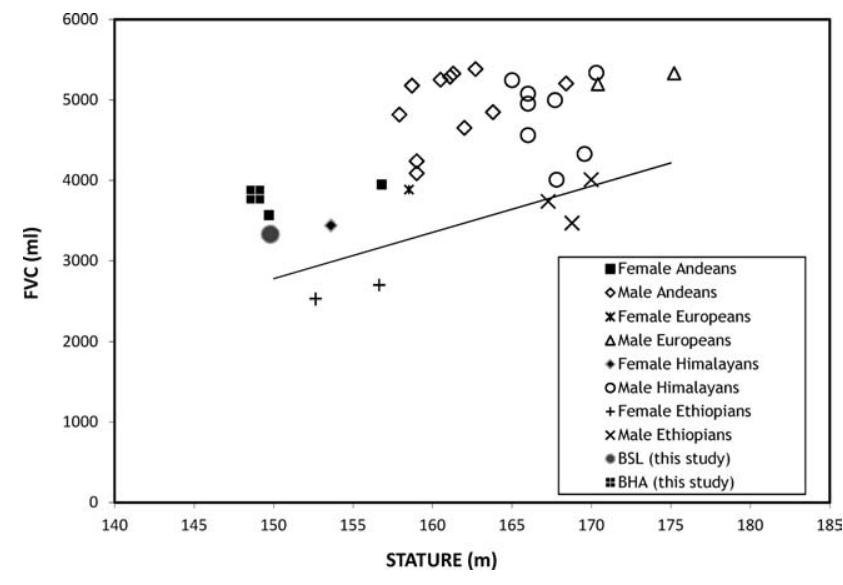

Fig. 3. Forced vital capacity (FVC in $\mathrm{ml}$ ) in male and female Andeans, Himalayans, and Europeans born and raised at high altitude plotted against stature. Reference line indicates the predicted FVC (cm) at sea-level (Polgar and Weng, 1979). Data are presented from Andeans (Boyce et al., 1974; Mueller et al., 1978; Greksa et al., 1987, 1994; Frisancho et al., 1997; Brutsaert et al., 1999), Himalayans (Droma et al., 1991; Weitz et al., 2002), European populations born and raised at altitude (Frisancho et al., 1997; Brutsaert et al., 1999) and Ethiopians (Harrison et al., 1969). Values from this study are included (BHA and BSL).

3.9501 (Mueller et al., 1978; Greksa et al., 1987, 1994; Frisancho et al., 1997).

In contrast to FVC, which is relatively easy to measure, there are fewer studies reporting RV and TLC in the literature, given the technical expertise necessary to obtain RV. Our results for both RV and TLC are 9-14\% lower than the values reported by Greksa et al. (1994) and Frisancho et al. (1997). Nevertheless, this could be explained mainly by differences in height, given that the BHA group is $\sim 10 \mathrm{~cm}$ shorter on average than high altitude female samples previously reported. Our results showed that TLC was about $19 \%$ higher in BHA, compared to BSL. More importantly, TLC differences between BHA and BSL were explained primarily by enlarged RV, followed by FVC, which are consistent with previous studies (Greksa et al., 1994). RV was $42 \%$ larger in BHA compared to BSL, whereas FVC was only $11 \%$ larger in BHA compared to BSL. It has been suggested that the smaller difference in FVC between highaltitude and sea-level born groups might be explained by other environmental factors. For example, Frisancho et al. (1997) reported that occupational activity levels were positively related to FVC. We did not officially document physical activity levels in our groups or socioeconomic status, but based on the brief information on the initial interviews, most volunteers were students, housewives, or engaged in informal commercial activities.

\section{Genetic components of pulmonary volumes}

Genetic effects have been inferred in previous studies from the comparison of study groups with different ancestries (Europeans vs. Quechuas) or from studies that used surnames and/or skin reflectance as a proxy measure of Andean ancestry (Greksa, 1996; Frisancho et al., 1997). In this study, we used AIMs to assess the NAAP of each subject. It is important to clarify that NAAP represents an estimate of Native American ancestry, and not uniquely Quechua ancestry, as the informa- tion for allele frequencies in this population is not available. However, the process of selection of individuals assured that only Quechua individuals (not individuals with diverse Native American ancestry) participated in the study, based on a priori criteria for recruiting described in the methodology. Previous publications have discussed the validity and benefits of this molecular approach; and several studies have detected meaningful associations between ancestry proportions and a specific phenotype, including skin color in populations with African ancestry (Shriver et al., 2003). More importantly, in Andean populations, NAAP has been used as an independent variable to evaluate the hypoxic ventilatory response (Brutsaert et al., 2005), smaller decrement in $\mathrm{VO}_{2}$ max from sea-level to altitude (Brutsaert et al., 2003), uterine artery blood flow (Wilson et al., 2007), and $\mathrm{O}_{2}$ delivery during pregnancy in Andean women (Julian et al., 2009).

In this study, we found a significant association of NAAP with RV, but not with FVC and TLC. Similarly, our research group had previously reported no association between FVC and NAAP in a sample of Quechua males. This result was attributed to lower precision and a narrow range of ancestry proportions (Brutsaert et al., 2004). Unfortunately, RV was not measured in males to be able to compare this pulmonary volume using the same methodology. In order to increase precision of the NAAP estimate, we augmented the number of AIMs used, but the narrow range of Quechua ancestry might have limited our ability to detect any association between FVC and NAAP. Indeed, this study might not have been optimal for the purpose of testing genetic hypotheses. First, we chose subjects who self-identified as Quechua, and whose NAAP was later confirmed by molecular analyses. This was effective for ensuring two well-matched study samples, to answer developmental questions, but it limited the range of NAAP and thus, our ability to test for an association between ancestry and pulmonary volumes. Second, the association found between RV and NAAP is significant $(P=0.004)$, but the amount of variation attributed to genetic factors is not high $\left(R^{2}=0.079\right)$. It is possible that a wider range of Quechua ancestry could have resulted in a stronger correlation for $\mathrm{RV}$ or even a positive association between NAAP and other pulmonary volumes. Another alternative is that the interaction between genetic and developmental factors might be necessary for the attainment of enlarged lung volumes. For example, Brutsaert et al. (1999) studied Quechuas and Europeans matched for their place of birth (sea level and high altitude) and found that, while both FVC and FEV were larger in Quechuas at high altitude, there was no difference in lung volumes between these two groups at sea-level. The study suggested that the enlarged volumes in Quechua populations are expressed when paired with exposure to a hypoxic environment during development. However, our results showed no interaction effects between NAAP and place of birth for any pulmonary volume. Similarly, in a previous study with males, no interaction effects between ancestry and birthplace were detected for FVC (Brutsaert et al., 2004).

In this study, both genetic and developmental components seem to play an important role in determining higher RV in this sample of Quechua females. Approximately, $20 \%$ of the variability for RV could be explained by developmental factors whereas $\sim 8 \%$ could be due to genetic factors (Table 3). In fact, when the two study 
groups were tested separately, RV was found to be positively associated to NAAP in the BSL group (as shown in Fig. 2), suggesting a role of genetic factors in the attainment of enlarged RV, even without the hypoxic stimulus during the process of development. Our results are partially consistent with a previous report by Frisancho et al. (1997), which indicated a 20-25\% contribution of developmental factors to explain the variability in residual lung volumes. However, unlike this study, they reported an equal contribution of genetic factors (20$25 \%$ of the variability). Greksa (1996) also reported significant correlations of lung volumes with skin reflectance in Aymara natives, suggesting an influence of genetic factors. We found that the contribution of genetic factors in the variability of FVC and TLC in females was minimal and nonsignificant $(0.2-1 \%)$, whereas the majority of the variability for FVC and TLC was explained by developmental factors (17.9 and 29.6\%, $P<0.001$, respectively), as shown in Table 3. The contradictory results could be explained by the fact that sample populations in each study could have differing levels of Quechua ancestry proportion, not to mention the differences in methodology (skin reflectance vs. AIMs) to assess ancestry. Indeed, Brutsaert et al. (2004) did not find a significant correlation between skin reflectance and AIMs, suggesting that results obtained from studies using skin reflectance might not be comparable vis-à-vis with studies using NAAP as indicators of ancestry. Finally, it is also possible that population samples in previous studies had a wider range of ancestry proportions than the sample in the current study.

\section{Functional aspects of enlarged lung volumes}

The enlarged pulmonary volumes of highlanders likely lead to higher diffusion capacities by increasing the total surface area of the alveoli (Frisancho, 1983), which is consistent with the hypothesis of adaptation at the level of the lung in Andean natives. Indeed, diffusion capacity is higher in high altitude natives compared to their sealevel counterparts, as well as acclimatized sojourners (DeGraff et al., 1970; Dempsey et al., 1971; Guleria et al., 1971; Wagner et al., 2002), and it is also higher in Andean children compared to lowlanders (Vargas et al., 1982). The benefits of enhanced diffusion capacities in highlanders could be especially important during exercise in hypoxia, where metabolic demands for oxygen uptake increase. However, it is still unclear whether enlarged lung volumes have an effect on exercise capacity at high altitude. We did not find an association between lung volumes and $\mathrm{VO}_{2}$ max tested at hypoxia in this group (data not shown) or in previous studies by our research group (Brutsaert et al., 1999). In contrast, Sun et al. (1990) reported a positive relationship between FVC and $\mathrm{VO}_{2}$ max in highland Tibetan males. The contradictory findings in the literature could be due to inadequate power, especially considering that $\mathrm{VO}_{2} \max$ is determined by a myriad of factors, with gas exchange at the lungs being only one of the many steps in the oxygen transport chain. However, it is possible that the beneficial effects of enhanced diffusion capacity are not expressed through higher aerobic capacities, but rather through the maintenance of arterial oxygen saturation during exercise at hypoxia (Schoene et al., 1990; Zhuang et al., 1996; Wagner et al., 2002), or by the maintenance of higher arterial oxygen saturation during pregnancy, leading to decreased infant mortality and enhanced fetal growth rates (Moore et al., 1986; Beall et al., 2004).

\section{Differential timing of developmental exposure to hypoxia}

Nearly all previous studies have shown that life at high altitude significantly increases pulmonary volumes, but the timing at which developmental factors contribute to lung growth has yet to be determined. Studies have suggested that the enhanced lung volumes of Andeans are mainly acquired during childhood and continue through adolescence (Frisancho, 1969; Mueller et al., 1978; Greksa et al., 1987). Infancy has been reported to be an important period as well, especially for the process of alveoli hyperplasia (Copland and Post, 2004), and during lung development, infancy could be particularly sensitive to the effects of hypoxia too. However, studies reporting pulmonary volumes in high altitude natives have not included an age distribution that incorporates infancy. Although pulmonary volumes have not been directly reported in highland infants, studies have suggested a more efficient $\mathrm{O}_{2}$ extraction in highland vs. lowland newborns (Mortola et al., 1992).

Frisancho et al. (1997) showed negative associations between age at migration to high altitude and RV, also suggesting a continuous effect of hypoxia during growth. These studies have been cross-sectional only, and longitudinal studies are required. In addition, all previous research has only evaluated post-natal developmental effects on lung growth. Developmental effects do not necessarily start after birth. Indeed, recent attention has been focused on the pre-natal environment and longterm effects on the adult phenotype (Barker, 1995). There is a well-documented association between low birth weight and chronic degenerative diseases and obesity (Barker et al., 1990, 1993; Phillips et al., 1994; Fall et al., 1995). The literature concerning the association between early life conditions and adult lung function is limited and shows conflicting results. While some studies have shown limited or no association between lung volumes and birth weight (Lawlor et al., 2005), others reported an association between low birth weight and lower pulmonary volumes, both in children (Kotecha et al., 2010) and adults (Canoy et al., 2007), suggesting that the environmental insults in utero could have an effect on the development of lungs later in life.

\section{CONCLUSION}

Like many previous studies, this paper shows that female high altitude natives have significantly larger pulmonary volumes than their lowland counterparts, after controlling for the effects of height and NAAP, using a migration/ancestry model. This confirms the importance of developmental factors in high altitude adaptation, specifically for the attainment of larger FVC and TLC. Moreover, genetic factors were found to play an important role as well, in the development of larger RV, but not for FVC or TLC. In summary, these results both support and extend previous research on high-altitude adaptation, and reiterate the importance of both developmental and genetic adaptation in the Andes.

\section{ACKNOWLEDGMENTS}

We are greatly indebted to the female volunteers in our study, who contributed their time and energy to participate in this research. 


\section{LITERATURE CITED}

Barker DJ. 1995. Fetal origins of coronary heart disease. BMJ 311:171-174.

Barker DJ, Bull AR, Osmond C, Simmonds SJ. 1990. Fetal and placental size and risk of hypertension in adult life. BMJ 301:259-262.

Barker DJ, Hales CN, Fall CH, Osmond C, Phipps K, Clark PM. 1993. Type 2 (non-insulin-dependent) diabetes mellitus, hypertension and hyperlipidaemia (syndrome $\mathrm{X}$ ): relation to reduced fetal growth. Diabetologia 36:62-67.

Bartlett D Jr, Remmers JE. 1971. Effects of high altitude exposure on the lungs of young rats. Respir Physiol 13:116-125.

Beall CM. 2000. Tibetan and Andean contrasts in adaptation to high-altitude hypoxia. Adv Exp Med Biol 475:63-74.

Beall CM, Cavalleri GL, Deng L, Elston RC, Gao Y, Knight J, Li C, Li JC, Liang Y, McCormack M, Montgomery HE, Pan H, Robbins PA, Shianna KV, Tam SC, Tsering N, Veeramah KR, Wang W, Wangdui P, Weale ME, Xu Y, Xu Z, Yang L, Zaman MJ, Zeng C, Zhang L, Zhang X, Zhaxi P, Zheng YT et al. 2010. Natural selection on EPAS1 (HIF2alpha) associated with low hemoglobin concentration in Tibetan highlanders. Proc Natl Acad Sci USA 107:11459-11464.

Beall CM, Song K, Elston RC, Goldstein MC. 2004. Higher offspring survival among Tibetan women with high oxygen saturation genotypes residing at 4,000 m. Proc Natl Acad Sci USA 101:14300-14304.

Bigham A, Bauchet M, Pinto D, Mao X, Akey JM, Mei R, Scherer SW, Julian CG, Wilson MJ, López Herráez D, Brutsaert T, Parra EJ, Moore LG, Shriver MD. 2010. Identifying signatures of natural selection in Tibetan and Andean populations using dense genome scan data. PLoS Genet 6. p ii: e1001116.

Bigham AW, Kiyamu M, León-Velarde F, Parra EJ, Rivera-Ch M, Shriver MD, Brutsaert TD. 2008. Angiotensin-converting enzyme genotype and arterial oxygen saturation at high altitude in Peruvian Quechua. High Alt Med Biol 9:167-178.

Bonilla C, Parra EJ, Pfaff CL, Dios S, Marshall JA, Hamman RF, Ferrell RE, Hoggart CL, McKeigue PM, Shriver MD. 2004. Admixture in the Hispanics of the San Luis Valley, Colorado, and its implications for complex trait gene mapping. Ann Hum Genet 68:139-153.

Boyce AJ, Haight JS, Rimmer DB, Harrison GA. 1974. Respiratory function in Peruvian Quechua Indians. Ann Hum Biol 1:137-148.

Brutsaert T, Parra E, Shriver M, Gamboa A, Palacios J, Rivera M, Rodriguez I, León-Velarde F. 2003. Spanish genetic admixture is associated with larger $\mathrm{V}(\mathrm{O} 2)$ max decrement from sea level to $4338 \mathrm{~m}$ in Peruvian Quechua. J Appl Physiol 92:519-528.

Brutsaert T, Parra E, Shriver M, Gamboa A, Rivera-Ch M, León-Velarde F. 2005. Ancestry explains the blunted ventilatory response to sustained hypoxia and lower exercise ventilation of Quechua altitude natives. Am J Physiol Regul Integr Comp Physiol 289:R225-R234.

Brutsaert TD, Parra E, Shriver M, Gamboa A, Palacios JA, Rivera M, Rodriguez I, León-Velarde F. 2004. Effects of birthplace and individual genetic admixture on lung volume and exercise phenotypes of Peruvian Quechua. Am J Phys Anthropol 123:390-398.

Brutsaert TD, Soria R, Caceres E, Spielvogel H, Haas JD. 1999. Effect of developmental and ancestral high altitude exposure on chest morphology and pulmonary function in Andean and European/North American natives. Am J Hum Biol 11:383-395.

Burri PH, Weibel ER. 1971. Morphometric estimation of pulmonary diffusion capacity. II. Effect of PO2 on the growing lung. Adaption of the growing rat lung to hypoxia and hyperoxia. Respir Physiol 1971:247-264.

Canoy D, Pekkanen J, Elliott P, Pouta A, Laitinen J, Hartikainen A-L, Zitting P, Patel S, Little MP, Jarvelin M-J. 2007. Early growth and adult respiratory function in men and women followed from the fetal period to adulthood. Thorax 62:396-402.

Chakraborty R, Barton SA, Ferrell RE, Schull WJ. 1989. Ethnicity determination by names among the Aymara of Chile and Bolivia. Hum Biol 61:159-177.
Copland I, Post M. 2004. Lung development and fetal lung growth. Paediatr Respir Rev 5 Suppl A:S259-64.

Cunningham EL, Brody JS, Jain BP. 1974. Lung growth induced by hypoxia. J Appl Physiol 37:362-366.

DeGraff AC Jr, Grover RF, Johnson RL Jr, Hammond JW Jr, Miller JM. 1970. Diffusing capacity of the lung in Caucasians native to 3,100 m. J Appl Physiol 29:71-76.

Dempsey JA, Reddan WG, Birnbaum ML, Forster HV, Thoden JS, Grover RF, Rankin J. 1971. Effects of acute through lifelong hypoxic exposure on exercise pulmonary gas-exchange. Respir Physiol 13:62-89.

Droma T, McCullough RG, McCullough RE, Zhuang JG, Cymerman A, Sun SF, Sutton JR, Moore LG. 1991. Increased vital and total lung capacities in Tibetan compared to Han residents of Lhasa (3,658 m). Am J Phys Anthropol 86:341-351.

Durnin JV, Womersley J. 1974. Body fat assessed from total body density and its estimation from skinfold thickness: measurements on 481 men and women aged from 16 to 72 years. Br J Nutr 32:77-97.

Fall CH, Osmond C, Barker DJ, Clark PM, Hales CN, Stirling Y, Meade TW. 1995. Fetal and infant growth and cardiovascular risk factors in women. BMJ 310:428-432.

Faridy EE, Sanii MR, Thiveris JA. 1988. Fetal lung growth: influence of maternal hypoxia and hyperoxia in rats. Respir Physiol 73:225-242.

Frisancho AR, Frisancho HG, Albalak R, Villain M, Vargas E, Soria R. 1997. Developmental, genetic and environmental components of lung volumes at high altitude. Am J Hum Biol 9:191-203.

Frisancho AR, Velásquez T, Sanchez J. 1973. Influence of developmental adaptation on lung function at high altitude. Hum Biol 45:583-594.

Frisancho AR. 1969. Human growth and pulmonary function of a high altitude Peruvian Quechua population. Hum Biol 91:365379 .

Frisancho R. 1983. The high altitude native. In: Sutton JR, Houston CS, Jones NL, editors. Hypoxia, exercise and altitude. New York: Alan R. Liss. p 383-407.

Frisancho AR. 2009. Developmental adaptation: where we go from here. Am J Hum Biol 21:694-703.

Greksa LP. 1986. Growth patterns of European and Amerindian high altitude natives. Curr Anthropol 22:72-73.

Greksa LP. 1990. Developmental responses to high-altitude hypoxia in Bolivian children of European ancestry: a test of the developmental adaptation hypothesis. Am J Hum Biol 2: 603-612.

Greksa LP. 1996. Evidence for a genetic basis to the enhanced total lung capacity of Andean highlanders. Hum Biol 68: 119-129.

Greksa LP, Spielvogel H, Caceres E. 1994. Total lung capacity in young highlanders of Aymara ancestry. Am J Phys Anthropol 94:477-486.

Greksa LP, Spielvogel H, Caceres E, Paredes-Fernandez L. 1987. Lung function of young Aymara highlanders. Ann Hum Biol 14:533-542.

Guleria JS, Pande JN, Sethi PK, Roy SB. 1971. Pulmonary diffusing capacity at high altitude. J Appl Physiol 31:536-543.

Hanis CL, Chakraborty R, Ferrell RE, Schull WJ. 1986. Individual admixture estimates: disease associations and individual risk of diabetes and gallbladder disease among MexicanAmericans in Starr County, Texas. Am J Phys Anthropol 70:433-441.

Harrison GA. 1966. Human adaptability with reference to the IBP proposals for high altitude research. In: Baker PT, Weiner JS, editors. The biology of human adaptability. Oxford: Clarendon Press. p 509-519.

Harrison GA, Kuchemann CF, Moore MAS, Boyce AJ, Baju T, Mourant AE, Godber MJ, Glasgow BG, Kopec AC, Tills D, Clegg EJ. 1969. The effects of altitudinal variation in Ethiopian populations. Philos Trans R Soc Lond 256:147-182.

Hochachka PW, Rupert JL, Monge C. 1999. Adaptation and conservation of physiological systems in the evolution of human hypoxia tolerance. Comp Biochem Physiol A Mol Integr Physiol 124:1-17. 
Johnson RL Jr., Cassidy SS, Grover RF, Schutte JE, Epstein RH. 1985. Functional capacities of lungs and thorax in beagles after prolonged residence at 3,100 m. J Appl Physiol 59:1773-1782.

Julian CG, Wilson MJ, Lopez M, Yamashiro H, Tellez W, Rodriguez A, Bigham AW, Shriver MD, Rodriguez C, Vargas E, Moore LG. 2009. Augmented uterine artery blood flow and oxygen delivery protect Andeans from altitude-associated reductions in fetal growth. Am J Physiol Regul Integr Comp Physiol 296:R1564-R1575.

Kotecha SJ, Watkins WJ, Heron J, Henderson J, Dunstan FD, Kotecha S. 2010. Spirometric lung function in school-aged children: effect of intrauterine growth retardation and catchup growth. Am J Respir Crit Care Med 181:969-974.

Lawlor DA, Ebrahim S, Davey Smith G. 2005. Association of birth weight with adult lung function: findings from the British women's heart and health study and a meta-analysis. Thorax 60:851-858.

Lechner AJ, Banchero N. 1980. Lung morphometry in guinea pigs acclimated to hypoxia during growth. Respir Physiol 42:155-169.

Monge MC. 1948. Acclimatization in the Andes. Baltimore, MD: John Hopkins University Press.

Moore LG. 2001. Human genetic adaptation to high altitude. High Alt Med Biol 2:257-279.

Moore LG, Brodeur P, Chumbe O, D’Brot J, Hofmeister S, Monge C. 1986. Maternal hypoxic ventilatory response, ventilation, and infant birth weight at 4,300 m. J Appl Physiol 60:1401-1406.

Mortola JP, Frappell PB, Frappell DE, Villena-Cabrera N, Villena-Cabrera M, Peña F. 1992. Ventilation and gaseous metabolism in infants born at high altitude, and their responses to hyperoxia. Am Rev Respir Dis 146:1206-1209.

Mueller WH, Yen F, Rothhammer F, Schull WJ. 1978. A multinational Andean genetic and health program. VI. Physiological measurements of lung function in a hypoxic environment. Hum Biol 50:489-513.

Parra EJ, Kittles RA, Shriver MD. 2004. Implications of correlations between skin color and genetic ancestry for biomedical research. Nat Genet 36:S54-S60.

Phillips DI, Barker DJ, Hales CN, Hirst S, Osmond C. 1994. Thinness at birth and insulin resistance in adult life. Diabetologia 37:150-154.

Polgar G, Weng TR. 1979. The functional development of the respiratory system from the period of gestation to adulthood. Am Rev Respir Dis 120:625-695.

Rupert JL, Hochachka PW. 2001. The evidence for hereditary factors contributing to high altitude adaptation in Andean natives: a review. High Alt Med Biol 2:235-256.

Schoene RB, Roach RC, Lahiri S, Peters Jr. RM, Hackett PH, Santolaya R. 1990. Increased diffusion capacity maintains arterial saturation during exercise in the Quechua Indians of Chilean Altiplano. Am J Hum Biol 2:663-668.

Sekhon H, Thurlbeck W. 1996a. Lung morphometric changes after exposure to hypobaria and/or hypoxia and undernutrition. Respir Physiol 106:99-107.

Sekhon HS, Thurlbeck WM. 1996b. Time course of lung growth following exposure to hypobaria and/or hypoxia in rats. Respir Physiol 105:241-252.
Shriver M, Parra E, Dios S, Bonilla C, Norton H, Jovel C, Pfaff C, Jones C, Massac A, Cameron N, Baron A, Jackson T, Argyropoulos G, Jin L, Hoggart CJ, McKeigue PM, Kittles RA. 2003. Skin pigmentation, biogeographical ancestry and admixture mapping. Hum Genet 112:387-399.

Simonson TS, Yang Y, Huff CD, Yun H, Qin G, Witherspoon DJ, Bai Z, Lorenzo FR, Xing J, Jorde LB, Prchal JT, Ge R. 2010. Genetic evidence for high-altitude adaptation in Tibet. Science 329:72-75.

Siri W. 1956. The gross composition of the body. Adv Biol Med Phys 4:239-280.

Sun SF, Droma TS, Zhang JG, Tao JX, Huang SY, McCullough RG, McCullough RE, Reeves CS, Reeves JT, Moore LG. 1990. Greater maximal O2 uptakes and vital capacities in Tibetan than Han residents of Lhasa. Respir Physiol 79:151-161.

Vargas E, Beard J, Haas J, Cudkowicz L. 1982. Pulmonary diffusing capacity in young Andean highland children. Respiration 43:330-335.

Velasquez T, Martinez C, Pezzia W, Gallardo N. 1968. Ventilatory effects of oxygen in high altitude natives. Resp Physiol 5:211-220.

Wagner PD, Araoz M, Boushel R, Calbet JA, Jessen B, Radergran G, Spielvogel H, Sondegaard H, Wagner H, Saltin B 2002. Pulmonary gas exchange and acid-base state at $5,260 \mathrm{~m}$ in high-altitude Bolivians and acclimatized lowlanders. J Appl Physiol 92:1393-400.

Weitz CA, Garruto RM, Chin C-T, Liu J-C, Liu R-L, He X. 2002. Lung function of Han Chinese born and raised near sea level and at high altitude in Western China. Am J Hum Biol 14:494-510.

Wilmore JH, Vodak PA, Parr RB, Girandola RN, Billing JE. 1980. Further simplification of a method for determination of residual lung volume. Med Sci Sports Exerc 12:216-218.

Wilson MJ, Lopez M, Vargas M, Julian C, Tellez W, Rodriguez A, Bigham A, Armaza F, Niermeyer S, Shriver M, Vargas E, Moore LG. 2007. Greater uterine artery blood flow during pregnancy in multigenerational (Andean) than shorter-term (European) high-altitude residents. Am J Physiol Regul Integr Comp Physiol 293:R1313-R1324.

Yi X, Liang Y, Huerta-Sanchez E, Jin X, Cuo ZX, Pool JE, Xu X, Jiang H, Vinckenbosch N, Korneliussen TS, Zheng H, Liu T, He W, Li K, Luo R, Nie X, Wu H, Zhao M, Cao H, Zou J, Shan Y, Li S, Yang Q, Asan, Ni P, Tian G, Xu J, Liu X, Jiang T, Wu R, Zhou G, Tang M, Qin J, Wang T, Feng S, Li G, Huasang, Luosang J, Wang W, Chen F, Wang Y, Zheng X, Li Z, Bianba Z, Yang G, Wang X, Tang S, Gao G, Chen Y, Luo Z, Gusang L, Cao Z, Zhang Q, Ouyang W, Ren X, Liang H, Zheng H, Huang Y, Li J, Bolund L, Kristiansen K, Li Y, Zhang Y, Zhang X, Li R, Li S, Yang H, Nielsen R, Wang J, Wang J. et al. 2010. Sequencing of 50 human exomes reveals adaptation to high altitude. Science 329:75-78.

Zhuang J, Droma T, Sutton JR, Groves BM, McCullough RE, McCullough RG, Sun S, Moore LG. 1996. Smaller alveolar-arterial $\mathrm{O} 2$ gradients in Tibetan than Han residents of Lhasa (3658 m). Respir Physiol 103:75-82. 